\title{
Geochemical Evaluation of Geopressued Geothermal Wellbore Cement
}

\author{
Kolawole Bello ${ }^{1}$ and Mileva Radonjic ${ }^{1}$ \\ ${ }^{1}$ Craft and Hawkins Department of Petroleum Engineering, 2131 Patrick F. Taylor Hall, Louisiana State \\ University, Baton Rouge, LA 70803
}

Geopressured reservoirs can serve as ample source of geothermal energy with temperatures as high as $140{ }^{\circ} \mathrm{C}$. Salinities are typically high in these reservoirs due to the dissolution of surrounding salt domes. Cement retrogression can occur under these geopressured geothermal conditions resulting from calcium silicate hydrate $\left[3 \mathrm{CaO} \cdot 2 \mathrm{SiO}_{2} \cdot 3 \mathrm{H}_{2} \mathrm{O}\right]$ phase in hydrated cement converting to alpha dicalcium silicate hydrate $\left[\left(\mathrm{Ca}_{2}\left(\mathrm{HSiO}_{4}\right)(\mathrm{OH})\right]\right.$ phase due to the high temperature. The higher the temperature, the quicker the rate of transformation of calcium silicate hydrates [1]. This conversion changes the structure of the hydrated cement leading to increased porosity, permeability and lowered compressive strength [2]. The real problem lies in the great increase of permeability which makes the cement susceptible to corrosive formation fluids.

In this experimental study, four 1.57 grams per cubic centimeter $(\mathrm{g} / \mathrm{cc})$ cement designs with water to cement ratio of 0.87 were aged at $140{ }^{\circ} \mathrm{C}$ for 30 days and compared to neat cement to study cement retrogression. All four cement slurry design contained class $\mathrm{H}$ cement and silica flour. Fine metakaolin, silica sand, steel fiber and glass fiber were added to the first, second, third and fourth sample respectively. These slurries were designed to provide a more durable design of wellbore cements capable to resist thermal fracturing and dissolution when in contact with low $\mathrm{pH}$ geofluids, such as brines rich in $\mathrm{CO}_{2}$.

Preliminary data on neat $1.57 \mathrm{~g} / \mathrm{cc}$ cement suggest that thermal loading can cause alterations in cement physical properties. Permeability of samples subjected to temperature changes are impacted, as well as porosity, as observed in pulse-decay permeability measurements. Higher permeability and porosity values in cements cores cured at high temperature shows the onset of strength retrogression. The microstructure and spatial elemental chemical composition obtained by electron microscopy and energy dispersive spectroscopy confirm the changes and provide an insight into the mechanism of these changes. Some of the main alterations are manifested in the amount and morphology of calcium silicate hydrates present as well as calcium hydroxide $\left[\mathrm{Ca}(\mathrm{OH})_{2}\right]$ and the pore-structure distribution within cement matrix.

Scanning electrom microscope (SEM) micrographs depicts the impact of temperature on cement microstructure, resulting in much larger calcium silicate hydrates size at $90{ }^{0} \mathrm{C}$ (Figure 1) compared to at ambient condition (Figure 2). With increase in temperature, the faster the rate of hydration of cement leading to fibrous calcium silicate hydrates growing from and replacing unhydrated tricalcium silicate $\left[3 \mathrm{CaO} \cdot \mathrm{SiO}_{2}\right]$ from the original cement clinker. More large calcium hydroxide crystals and unhydrated tricalcium silicate were also observed in cement samples cured at ambient condition than those at $90{ }^{0} \mathrm{C}$ (outlined in Figures 1) as a result of slower rate of hydration. Packing of large fibrous calcium silicate hydrate causes increased porosity at high temperature. This means that cements cured at $90{ }^{0} \mathrm{C}$ have larger pore spaces than those cured at ambient conditions. The presence of larger pore spaces increases connectivity in porous media like cement. 


\section{References:}

[1] Taylor, H. F. W. in "Cement Chemistry" $2^{\text {nd }}$ ed., (Thomas Telford Services, London) p. 339

[2] Nelson, E.B. et al in "Well Cementing”, $2^{\text {nd }}$ ed., (Schlumberger, Houston) p. 330.

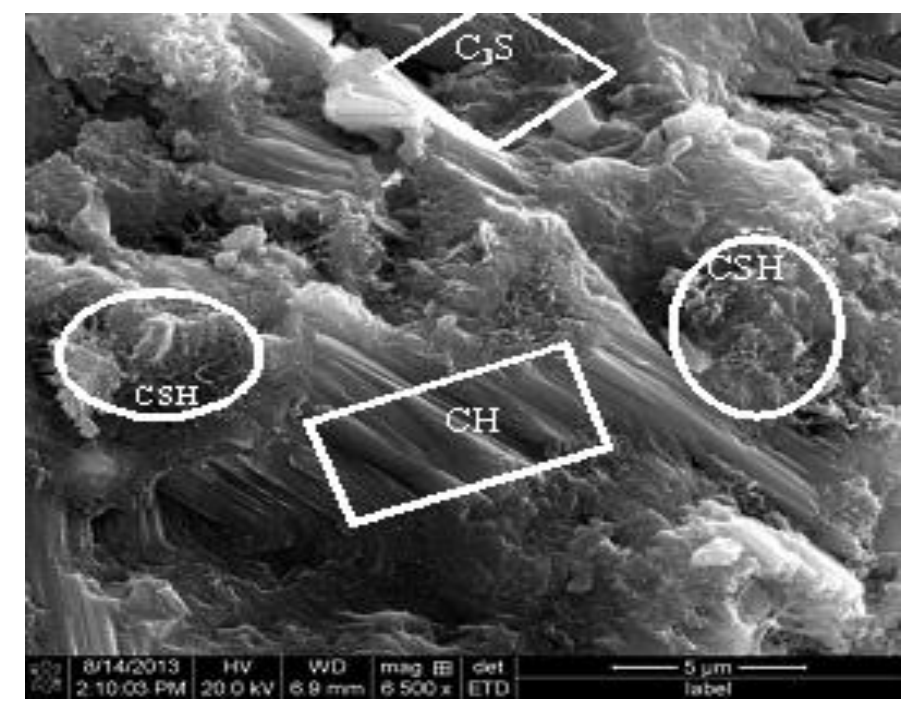

Figure 1. SEM image of control sample cured at ambient conditions in a water bath shows large amount of calcium hydroxide $(\mathrm{CH})$, unhydrated tricalcium silicate $\left(\mathrm{C}_{3} \mathrm{~S}\right)$ and fine calcium silicate hydrates (CSH).

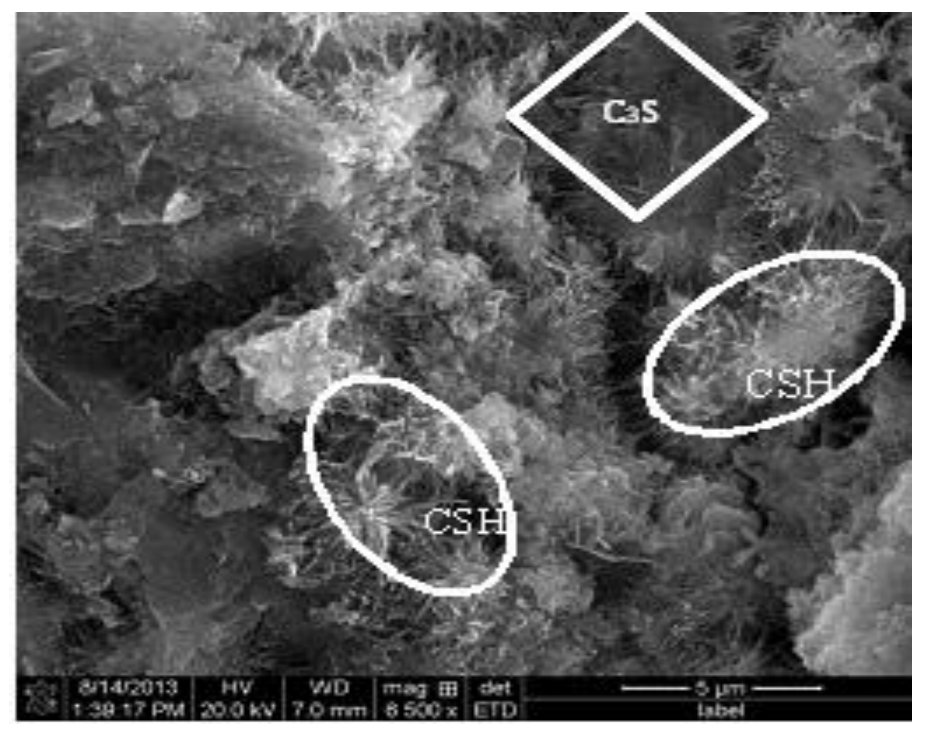

Figure 2. SEM image of $1.97 \mathrm{~g} / \mathrm{cc}$ cement (w/c: 0.38) cured at $90^{\circ} \mathrm{C}$ and $100 \% \mathrm{RH}$ depicting large, coarse calcium silicate hydrates $(\mathrm{CSH})$ and unhydrated tricalcium silicate $\left(\mathrm{C}_{3} \mathrm{~S}\right)$. Packing of large fibrous calcium silicate hydrate causes increased porosity at high temperature. 